\title{
Role of G Protein-Coupled Estrogen Receptor in Cancer Progression
}

\author{
Joohee Jung \\ College of Pharmacy, Duksung Women's University, Seoul, Korea
}

\begin{abstract}
Cancer is the leading cause of mortality worldwide. In cancer progression, sex hormones and their receptors are thought to be major factors. Many studies have reported the effects of estrogen and estrogen receptors (ERs) in cancer development and progression. Among them, G protein-coupled estrogen receptor (GPER), a G proteincoupled receptor, has been identified as an estrogen membrane receptor unrelated to nuclear ER. The mechanism of GPER, including its biological action, function, and role, has been studied in various cancer types. In this review, we discuss the relation between GPER and estrogen or estrogen agonists/antagonists and cancer progression.
\end{abstract}

Key words: GPER, Cancer progression, Estrogen, G1

\section{INTRODUCTION}

Understanding cancer progression, a major cause of mortality, plays an important role in clinical applications and extension of healthy life span. Cancer progression consists of multistage carcinogenesis and metastasis programs (1), which are caused through complex pathways including genetic and environmental factors. Among them, sex hormones and their receptors are attractive factors for promoting cancer progression. The effect of sex hormones and their receptors on cancer progression has been studied for a long time. Typically, breast cancer and prostate cancer (PC) are known to be related to sex hormone. However, the role of androgen receptor and estrogen receptors
(ERs) are not sufficient to drive cancer progression. Recently, GPR30, also called G-protein coupled estrogen receptor (GPER), has been identified.

GPER is a G-protein coupled receptor, which are seventransmembrane receptors (2) and also a type of ER (3); however, it does not have the same mechanism of action as typical nuclear receptors, such as ER $\alpha$ and $\beta$. GPER is well known to play a role of substituted ER in physiological function from the model of GPER knockout mice (4). GPER is a mediator of estrogen in nervous system $(5,6)$, immune system (7), cardiovascular system $(8,9)$, bone metabolism (10), glucose metabolism in pancreas (11), kidney function (12), reproductive system and cancer (1316) (Table 1). Among them, this review focuses on the
Correspondence to: Joohee Jung, College of Pharmacy, Duksung Women's University, 33, 144-gil, Samyang-ro, Dobong-gu, Seoul 01369, Korea

E-mail: joohee@duksung.ac.kr

This is an Open-Access article distributed under the terms of the Creative Commons Attribution Non-Commercial License (http:// creativecommons.org/licenses/by-nc/3.0) which permits unrestricted non-commercial use, distribution, and reproduction in any medium, provided the original work is properly cited.
List of abbreviations: $A R$, androgen receptor; CAFs, cancer-associated fibroblasts; $C R C$, colorectal cancer; EC, endometrial cancer; EGFR, epithelial growth factor receptor; ER, estrogen receptor; ERK, extracellular-signal-regulated kinase; ERT, estrogen replacement therapy; FAS, fatty acid synthase; $G n R$, gonadotrophin receptor; $\mathrm{GnRH}$, gonadotrophin releasing hormone; GPER, G protein-coupled estrogen receptor; HCC, hepatocellular carcinoma; IGF-I, insulin-like growth factor-l; KO, knockout; MAPK, mitogenactivated protein kinase; MMP, matrix metalloproteinase; NHERF1, $\mathrm{Na}^{+} / \mathrm{H}^{+}$exchanger regulatory factor; PC, prostate cancer; PI3K, phosphoinositide 3-kinase; PR, progesterone receptor; TAZ, transcriptional coactivator with PDZ-binding domain; TF, transcriptional factor; TK, tyrosine kinases; TNBC, triple-negative breast cancer; YAP, yes-associated protein 1. 
Table 1. The role of GPER in physiology

\begin{tabular}{llc}
\hline \multicolumn{1}{c}{ System } & \multicolumn{1}{c}{ Function } & Reference \\
\hline Nervous system & Release of neurotransmitter, neurogeneration & $(5,6,14)$ \\
Immune system & Thymocyte apoptosis & $(7)$ \\
Cardiovascular system & Regulation of vascular tone & $(8,9,14)$ \\
& Protection from myocardial injury \\
Bone & Bone mineral density & $(10,14-16)$ \\
Pancreas & Maintain the metabolic function of insulin & $(11,14-16)$ \\
Kidney & Protection of hypertensive nephropathy & $(12)$ \\
\hline
\end{tabular}

role of GPER in tumor progression.

\section{GPER-ACTIVATED SIGNALING PATHWAYS}

Estrogen binds to and activates GPER in plasma membrane (3). Tamoxifen, ICI 182,780, o, p'-dichlorodiphenyl dichloroethylene can also act as agonists of GPER (3). Furthermore, G1 has been identified as an agonist of GPER, and G15 has been found to be a GPER antagonist (17). Ligand-bound GPER induces a cascade response and triggers several pathways leading to cell proliferation, gene expression, cell growth, and tumor progression (Fig. 1). It activates adenylyl cyclase, cAMP, calcium mobilization, and mitogen-activated protein kinase (MAPK). Additionally, it relates to the phosphoinositide 3-kinase (PI3K)/Akt pathway, the Hippo/yes-associated protein 1 (YAP)/transcriptional coactivator with PDZ-binding domain (TAZ) pathway, and epithelial growth factor receptor (EGFR)/ MARL transactivation (18-21). Activated GPER induces the release of calcium from the endoplasmic reticulum, which activates Src-like nonreceptor tyrosine kinases

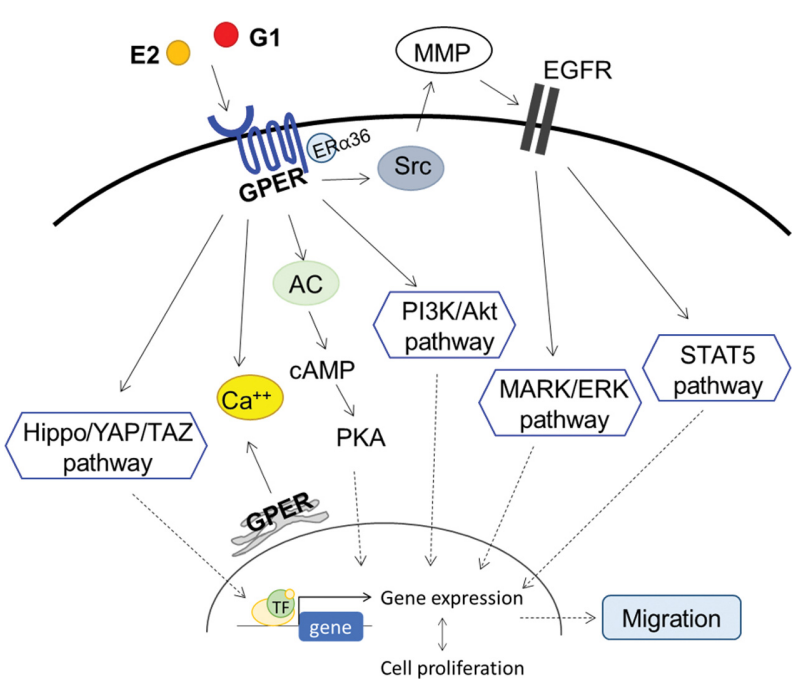

Fig. 1. Proposed mechanism of GPER in cancer cells. AC, adenylyl cyclase; PKA, protein kinase A; MMP, matrix metalloproteinase; EGFR, epithelial growth factor receptor; TF, transcriptional factor.
(TKs). TKs then promote matrix metalloproteinase (MMP) activation and EGFR activation (12). EGFR phosphorylation activates the STAT5 and MAPK/extracellular regulated kinase (ERK) pathways. These pathways are affected by ER- $\alpha 36$ expression, which is induced by GPER, and involved in cell proliferation in breast cancer (22). Activation of these pathways via GPER might contribute to progression in various cancers.

\section{GPER IN BREAST CANCER}

The role of GPER has been best studied in breast cancer, which is more prevalent in women than men. GPER is known to contribute to cancer cell proliferation, migration, and invasion in breast cancer (18). From cDNA library screening, the expression of GPER is shown in ER-positive breast cancer more than in ER-negative breast cancer (23). GPER signaling modulates miR-144 expression and stimulates cancer progression in the breast (24). GPER is highly expressed in triple negative breast cancer (TNBC), GPER/ERK signaling contributes to tumor progression in TNBC (25), and GPER knock-down reduces proliferation in TNBC. While GPER knockout mice do develop tumors, their histological grade and necrosis score are lower than those of control mice (26). Furthermore, an agonist of gonadotrophin releasing hormone $(\mathrm{GnRH})$ receptor inhibits GPER signaling in ER $\alpha$-negative breast cancer, and cancer cell proliferation is suppressed (27). $\mathrm{Na}^{+} /$ $\mathrm{H}^{+}$exchanger regulatory factor (NHERF1) is a tumor suppressor (28) related to GPER expression and stability in ER-positive breast cancer (18). NHERF1 overexpression inhibits GPER-mediated proliferation in MDA-MB-231 (TNBC) (Table 2) cells and in early stage of TNBC (29). However, absence of GPER does not affect early tumor

Table 2. Cancer cell lines used in vitro studies

\begin{tabular}{ll}
\hline \hline \multicolumn{1}{c}{ Cancer } & \multicolumn{1}{c}{ Cell lines } \\
\hline Breast cancer & $\begin{array}{c}\text { MDA-MB-231 } \\
\text { (triple negative breast cancer) }\end{array}$ \\
Ovarian cancer & OVCAR5, OVCAR-3, SKOV-3 \\
Endometrial cancer & Hec50 \\
Lung cancer & A549 \\
\hline
\end{tabular}


initiation or proliferation (30). GPER inhibitors, such as estriol (31) and gefitinib (32), and inhibition of GPER expression by inhibition of growth hormone receptor (33) prevent the $17 \beta$-estradiol-induced growth of TNBC. Furthermore, knockdown of ER- $\alpha 36$, which is induced by GPER, reduces estrogen resistance, proliferation, migration and invasion in breast cancer (28).

As with breast cancer cells, the tumor microenvironment contributes to cancer progression. Unlike GPER, which is a membrane receptor, GPER p16L, caused by a single nucleotide polymorphism, localizes to the nucleus of cancer-associated fibroblasts (CAFs) and acts as a transcription factor. GPER p16L induces the secretion of paracrine factors, which promotes cancer cell migration. Indeed, coculture of MDA-MB-231 cells with CAFs treated with estrogen increases migration of the MDA-MB-231 cells $(34,35)$.

\section{GPER IN OVARIAN CANCER}

A cohort study in the United States showed a correlation between estrogen replacement therapy and ovarian cancer (Table 2), but a meta-analysis found no such association $(30,36)$. Similarly, the estrogen-binding role of GPER is controversial in ovarian cancer. GPER is expressed in both the nuclears and cytosol in ovarian cancer, and nuclear GPER is a predictive factor of poor survival in ovarian cancer $(37,38)$. Furthermore, estrogen-activated GPER promotes cell proliferation, migration and invasion in ER-negative ovarian cancer (39), and high expression of GPER is correlated with tumor size and stage. High GPER is also associated with MMP9 expression (36), which induces invasion and migration in OVCAR5 cells (40). High GFER expression in ovarian cancer also induces lymph node metastasis, which decreases survival in ERnegative ovarian cancer patients. Moreover, GPER, independent of estrogen binding, promotes proliferation, migration and invasion in ER-positive SKOV-3 cells (41). Additionally, GnRH receptor agonist inhibits ERs signaling in GPER and ER-positive ovarian cancer cells (27). In contrast, high GPER expression predicts longer survival in gonadotrophin receptor (GnR)-negative patients $(42,43)$. GPER expression is lower in ovarian cancer than in benign and low-malignant tumors (44), and GPER-positive ovarian cancer patients have a significantly higher 2year disease-free survival than GPER-negative patients, indicating GPER acts as a tumor suppressor in ovarian cancer. G1, a GPER agonist, induces G2/M phase arrest and apoptosis through cyclin $\mathrm{B} 1, \mathrm{Cdc} 2$, and phosphorylated histone $\mathrm{H} 3$ in SKOV-3 and OVCAR-3 cells (44).

\section{GPER IN ENDOMETRIAL CANCER}

Endometrial cancer (EC) is one of the gynecologic cancers in which estrogen signaling causes proliferation.
Therefore, estrogen-activated receptors affect EC progression, and ER-negative EC has a lower survival rate than ER-positive EC. GPER is present in EC, although expression differs depending on cell type and tumor grade (45). GPER is overexpressed in ER- and progesterone receptor (PR)-negative cancer and is associated with myometrial invasion and poor survival (46). GPER is overexpressed in ER $\alpha$-negative Hec50 cells (Table 2), and GPER agonists enhance tumor growth in Hec50-derived xenografts (47). Tamoxifen, acting as a GPER agonist, increases tumor proliferation through cyclin D1, ERK, and EGFR (48). GPER mRNA levels are reduced in EC as compared to normal endometrial tissue (45). miRNA-424 suppresses E2F7 and E2F6 and inhibits cell proliferation and invasion via GPER in EC tissues (49,50). Additionally, progesterone receptor mRNA expression is related to GPER mRNA expression (45). Loss of GPER in ER-positive patients indicates poor prognosis and promotes tumor progression (51).

\section{GPER IN LUNG CANCER}

GPER expression is also high in lung cancer. GPER expression is high in human non-small cell lung cancer cell lines, other than A549 cells (Table 2), and normal lung bronchial epithelial cells (52). High GPER expression is associated with high ER $\beta$ expression in lung cancer (17). GPER signaling induces MMPs in human lung cancer cells (53). Metastasis is higher in cells with GPER expression than in large cell carcinoma, squamous cell carcinoma or adenocarcinoma (52), and lung metastasis is dramatically decreased in GPER knockout (KO) mice. GPER acts as a modulator of neoplastic transformation via PI3K/IKK/ $\mathrm{NF}-\gamma \mathrm{B}$ signaling (54-56). Migration stimulation is induced by GPER-associated activation of insulin-like growth factor-I (IGF-I)/IGF-IR via ERK, p38, and Akt activation (57).

\section{GPER IN COLORECTAL CANCER}

GPER acts as a tumor suppressor in colorectal cancer (CRC). In CRC progression, the GPER promoter has increased methylation and histone $\mathrm{H} 3$ deacetylation, and GPER expression is negatively correlated with increased stage and lymph node metastasis. Additionally, higher GPER expression is associated with longer survival. However, treatment with G-1 inhibits tumor growth via ROS, ERK $1 / 2$ activation, and GSK-3 $\beta$ activation/p65(NF- $\gamma$ B) suppression (58). Estrogen accelerates the proliferation of CRC because conjugated estrogen is activated by steroid sulfatase via GPER $(56,59)$. Furthermore, GPER regulates the expression of fatty acid synthase, which induces CAFs and contributes to cancer progression (60). E2-activated GPER contributes to migration and proliferation in hypoxia-induced CRC cells (61), and hormone replacement therapy may be associated with CRC progression (59). 


\section{GPER IN ADRENOCORTICAL CARCINOMA}

GPER agonists suppress adrenocortical carcinoma proliferation via cell cycle arrest, DNA damage, and apoptosis via ERK1/2 activation (62).

\section{GPER IN PROSTATE CANCER}

G1, a GPER agonist, inhibits the growth of PC cells and xenograft models via ERK1/2 and p21 activation (63-66). Furthermore, GPER expression is higher in castrationresistant PC cells than in androgen-sensitive PC cells, and G1 inhibits the growth of castration-resistant $\mathrm{PC}$ via necrosis (67). In contrast, high GPER levels in CAFs decrease $\mathrm{ER} \alpha$ expression, which promotes the proliferation and migration of prostate stromal cells (68). PC is associated with testosterone, but older men have decreased testosterone level. Nevertheless, xeno-estrogens and poor diet increase aromatase activation, which causes estrogen levels to increase. This increased estrogen activates ER $\alpha$ and GPER activation, which promotes PC (69).

\section{DISCUSSION}

The role of GPER in tumor progression differs depending on tumor stage, site, and environment. GPER expression is high in ER-negative cancer, and estrogen signaling via GPER promotes cancer progression. However, high GPER expression increases survival in ovarian cancer, even though the levels are lower than those in normal cells. Moreover, a GPER selective agonist, G1, suppresses tumor proliferation in CRC, PC, and adrenocortical carcinoma. Thus, GPER expression and its activators (estrogen and G1) should be considered, along with ER $\alpha, E R \beta, P R$, and $\mathrm{GnR}$, when examining cancer progression.

\section{ACKNOWLEDGMENTS}

This research was supported by the Bio \& Medical Technology Development Program of the NRF funded by the Korean Government (2015M3A9B6074045) and the NRF grant funded by the Korea government, MSIT (2017R1A2B4008254).

\section{CONFLICT OF INTEREST}

The author has no conflicts of interest to declare.

Received October 4, 2018; Revised November 12, 2018; Accepted November 22, 2018

\section{REFERENCES}

1. Klaassen, C.D., Watkins, J.B. and Casarett, L.J. (2010)
Casarett \& Doull's Essentials of Toxicology (2nd edition), McGraw-Hill Medical, New York.

2. O’Dowd, B.F., Nguyen, T., Marchese, A., Cheng, R., Lynch, K.R., Heng, H.H., Kolakowski, L.F., Jr. and George, S.R. (1998) Discovery of three novel G-protein-coupled receptor genes. Genomics, 47, 310-313.

3. Thomas, P., Pang, Y., Filardo, E.J. and Dong, J. (2005) Identity of an estrogen membrane receptor coupled to a $\mathrm{G}$ protein in human breast cancer cells. Endocrinology, 146, 624632.

4. Prossnitz, E.R. and Hathaway, H.J. (2015) What have we learned about GPER function in physiology and disease from knockout mice? J. Steroid Biochem. Mol. Biol., 153, 114-126.

5. Lu, C.L. and Herndon, C. (2017) New roles for neuronal estrogen receptors. Neurogastroenterol. Motil., 29, doi: 10.1111/nmo.13121 [Epub ahead of print].

6. Hadjimarkou, M.M. and Vasudevan, N. (2018) GPER1/ GPR30 in the brain: crosstalk with classical estrogen receptors and implications for behavior. J. Steroid Biochem. Mol. Biol., 176, 57-64.

7. Olde, B. and Leeb-Lundberg, L.M. (2009) GPR30/GPER1: searching for a role in estrogen physiology. Trends Endocrinol. Metab., 20, 409-416.

8. Meyer, M.R., Prossnitz, E.R. and Barton, M. (2011) GPER/ GPR30 and regulation of vascular tone and blood pressure. Immunol. Endocr. Metab. Agents Med. Chem., 11, 255-261.

9. Meyer, M.R., Prossnitz, E.R. and Barton, M. (2011) The G protein-coupled estrogen receptor GPER/GPR30 as a regulator of cardiovascular function. Vascul. Pharmacol., 55, 1725.

10. Ohlsson, C. and Vandenput, L. (2009) The role of estrogens for male bone health. Eur. J. Endocrinol., 160, 883-889.

11. Sharma, G. and Prossnitz, E.R. (2011) Mechanisms of estradiol-induced insulin secretion by the $G$ protein-coupled estrogen receptor GPR30/GPER in pancreatic beta-cells. Endocrinology, 152, 3030-3039.

12. Filardo, E.J. and Thomas, P. (2012) Minireview: G proteincoupled estrogen receptor-1, GPER-1: its mechanism of action and role in female reproductive cancer, renal and vascular physiology. Endocrinology, 153, 2953-2962.

13. Prossnitz, E.R. and Barton, M. (2014) Estrogen biology: new insights into GPER function and clinical opportunities. Mol. Cell. Endocrinol., 389, 71-83.

14. Prossnitz, E.R. and Barton, M. (2011) The G-protein-coupled estrogen receptor GPER in health and disease. Nat. Rev. Endocrinol., 7, 715-726.

15. Sharma, G. and Prossnitz, E.R. (2017) G-protein-coupled estrogen receptor (GPER) and sex-specific metabolic homeostasis. Adv. Exp. Med. Biol., 1043, 427-453.

16. Sharma, G., Mauvais-Jarvis, F. and Prossnitz, E.R. (2018) Roles of G protein-coupled estrogen receptor GPER in metabolic regulation. J. Steroid Biochem. Mol. Biol., 176, 31-37.

17. Liu, C., Liao, Y., Fan, S., Fu, X., Xiong, J., Zhou, S., Zou, M. and Wang, J. (2017) G-protein-coupled estrogen receptor antagonist G15 decreases estrogen-induced development of non-small cell lung cancer. Oncol. Res. doi: 10.3727/ 096504017X15035795904677 [Epub ahead of print].

18. Meng, R., Qin, Q., Xiong, Y., Wang, Y., Zheng, J., Zhao, Y., 
Tao, T., Wang, Q., Liu, H., Wang, S., Jiang, W.G. and He, J. (2016) NHERF1, a novel GPER associated protein, increases stability and activation of GPER in ER-positive breast cancer. Oncotarget, 7, 54983-54997.

19. Prossnitz, E.R. and Barton, M. (2009) Signaling, physiological functions and clinical relevance of the $G$ protein-coupled estrogen receptor GPER. Prostaglandins Other Lipid Mediat., 89, 89-97.

20. Prossnitz, E.R., Arterburn, J.B., Smith, H.O., Oprea, T.I., Sklar, L.A. and Hathaway, H.J. (2008) Estrogen signaling through the transmembrane $\mathrm{G}$ protein-coupled receptor GPR30. Annu. Rev. Physiol., 70, 165-190.

21. Ariazi, E.A., Brailoiu, E., Yerrum, S., Shupp, H.A., Slifker, M.J., Cunliffe, H.E., Black, M.A., Donato, A.L., Arterburn, J.B., Oprea, T.I., Prossnitz, E.R., Dun, N.J. and Jordan, V.C. (2010) The G protein-coupled receptor GPR30 inhibits proliferation of estrogen receptor-positive breast cancer cells. Cancer Res., 70, 1184-1194.

22. Gu, Y., Chen, T., Lopez, E., Wu, W., Wang, X., Cao, J. and Teng, L. (2014) The therapeutic target of estrogen receptoralpha36 in estrogen-dependent tumors. J. Transl. Med., 12, 16.

23. Carmeci, C., Thompson, D.A., Ring, H.Z., Francke, U. and Weigel, R.J. (1997) Identification of a gene (GPR30) with homology to the G-protein-coupled receptor superfamily associated with estrogen receptor expression in breast cancer. Genomics, 45, 607-617.

24. Vivacqua, A., De Marco, P., Santolla, M.F., Cirillo, F., Pellegrino, M., Panno, M.L., Abonante, S. and Maggiolini, M. (2015) Estrogenic gper signaling regulates mir144 expression in cancer cells and cancer-associated fibroblasts (cafs). Oncotarget, 6, 16573-16587.

25. Yu, T., Liu, M., Luo, H., Wu, C., Tang, X., Tang, S., Hu, P., Yan, Y., Wang, Z. and Tu, G. (2014) GPER mediates enhanced cell viability and motility via non-genomic signaling induced by 17 beta-estradiol in triple-negative breast cancer cells. $J$. Steroid Biochem. Mol. Biol., 143, 392-403.

26. Girgert, R., Emons, G. and Grundker, C. (2012) Inactivation of GPR30 reduces growth of triple-negative breast cancer cells: possible application in targeted therapy. Breast Cancer Res. Treat., 134, 199-205.

27. Grundker, C. and Emons, G. (2017) The role of gonadotropin-releasing hormone in cancer cell proliferation and metastasis. Front. Endocrinol. (Lausanne), 8, 187.

28. Georgescu, M.M., Morales, F.C., Molina, J.R. and Hayashi, Y. (2008) Roles of NHERF1/EBP50 in cancer. Curr. Mol. Med., 8, 459-468.

29. Wang, Y., Peng, Z., Meng, R., Tao, T., Wang, Q., Zhao, C., Liu, H., Song, R., Zheng, J., Qin, Q. and He, J. (2017) NHERF1 inhibits proliferation of triple-negative breast cancer cells by suppressing GPER signaling. Oncol. Rep., 38, 221-228.

30. Marjon, N.A., Hu, C., Hathaway, H.J. and Prossnitz, E.R. (2014) G protein-coupled estrogen receptor regulates mammary tumorigenesis and metastasis. Mol. Cancer Res., 12, 1644-1654.

31. Girgert, R., Emons, G. and Grundker, C. (2014) Inhibition of GPR30 by estriol prevents growth stimulation of triple-negative breast cancer cells by 17 beta-estradiol. BMC Cancer,
14, 935.

32. Girgert, R., Emons, G. and Grundker, C. (2017) 17betaestradiol-induced growth of triple-negative breast cancer cells is prevented by the reduction of GPER expression after treatment with gefitinib. Oncol. Rep., 37, 1212-1218.

33. Girgert, R., Emons, G. and Grundker, C. (2018) Inhibition of growth hormone receptor by Somavert reduces expression of GPER and prevents growth stimulation of triple-negative breast cancer by 17beta-estradiol. Oncol. Lett., 15, 95599566.

34. Cirillo, F., Pellegrino, M., Malivindi, R., Rago, V., Avino, S., Muto, L., Dolce, V., Vivacqua, A., Rigiracciolo, D.C., De Marco, P., Sebastiani, A., Abonante, S., Nakajima, M., Lappano, R. and Maggiolini, M. (2017) GPER is involved in the regulation of the estrogen-metabolizing CYP1B1 enzyme in breast cancer. Oncotarget, 8, 106608-106624.

35. Lappano, R. and Maggiolini, M. (2018) GPER is involved in the functional liaison between breast tumor cells and cancerassociated fibroblasts (CAFs). J. Steroid Biochem. Mol. Biol., 176, 49-56.

36. Rodriguez, C., Patel, A.V., Calle, E.E., Jacob, E.J. and Thun, M.J. (2001) Estrogen replacement therapy and ovarian cancer mortality in a large prospective study of US women. JAMA, 285, 1460-1465.

37. Zhu, C.X., Xiong, W., Wang, M.L., Yang, J., Shi, H.J., Chen, H.Q. and Niu, G. (2018) Nuclear G protein-coupled oestrogen receptor (GPR30) predicts poor survival in patients with ovarian cancer. J. Int. Med. Res., 46, 723-731.

38. Smith, H.O., Arias-Pulido, H., Kuo, D.Y., Howard, T., Qualls, C.R., Lee, S.J., Verschraegen, C.F., Hathaway, H.J., Joste, N.E. and Prossnitz, E.R. (2009) GPR30 predicts poor survival for ovarian cancer. Gynecologic Oncology, 114, 465-471.

39. Liu, H., Yan, Y., Wen, H., Jiang, X., Cao, X., Zhang, G. and Liu, G. (2014) A novel estrogen receptor GPER mediates proliferation induced by 17 beta-estradiol and selective GPER agonist G-1 in estrogen receptor alpha (ERalpha)negative ovarian cancer cells. Cell Biol. Int., 38, 631-638.

40. Yan, Y., Liu, H., Wen, H., Jiang, X., Cao, X., Zhang, G. and Liu, G. (2013) The novel estrogen receptor GPER regulates the migration and invasion of ovarian cancer cells. Mol. Cell. Biochem., 378, 1-7.

41. Yan, Y., Jiang, X., Zhao, Y., Wen, H. and Liu, G. (2015) Role of GPER on proliferation, migration and invasion in ligandindependent manner in human ovarian cancer cell line SKOV3. Cell Biochem. Funct., 33, 552-559.

42. Heublein, S., Mayr, D., Vrekoussis, T., Friese, K., Hofmann, S.S., Jeschke, U. and Lenhard, M. (2013) The G-protein coupled estrogen receptor (GPER/GPR30) is a gonadotropin receptor dependent positive prognosticator in ovarian carcinoma patients. PLOS ONE, $\mathbf{8}$, e71791.

43. Zhang, Q., Madden, N.E., Wong, A.S.T., Chow, B.K.C. and Lee, L.T.O. (2017) The role of endocrine G protein-coupled receptors in ovarian cancer progression. Front. Endocrinol. (Lausanne), 8, 66.

44. Ignatov, T., Modl, S., Thulig, M., Weissenborn, C., Treeck, O., Ortmann, O., Zenclussen, A., Costa, S.D., Kalinski, T. and Ignatov, A. (2013) GPER-1 acts as a tumor suppressor in ovarian cancer. J. Ovarian Res., 6, 51. 
45. Skrzypczak, M., Schuler, S., Lattrich, C., Ignatov, A., Ortmann, O. and Treeck, O. (2013) G protein-coupled estrogen receptor (GPER) expression in endometrial adenocarcinoma and effect of agonist G-1 on growth of endometrial adenocarcinoma cell lines. Steroids, 78, 1087-1091.

46. Smith, H.O., Leslie, K.K., Singh, M., Qualls, C.R., Revankar, C.M., Joste, N.E. and Prossnitz, E.R. (2007) GPR30: a novel indicator of poor survival for endometrial carcinoma. Am. J. Obstet. Gynecol., 196, 386.e1-386.e11.

47. Petrie, W.K., Dennis, M.K., Hu, C., Dai, D., Arterburn, J.B., Smith, H.O., Hathaway, H.J. and Prossnitz, E.R. (2013) G protein-coupled estrogen receptor-selective ligands modulate endometrial tumor growth. Obstet. Gynecol. Int., 2013, 472720.

48. Zhang, L., Li, Y., Lan, L., Liu, R., Wu, Y., Qu, Q. and Wen, K. (2016) Tamoxifen has a proliferative effect in endometrial carcinoma mediated via the GPER/EGFR/ERK/cyclin D1 pathway: a retrospective study and an in vitro study. Mol. Cell. Endocrinol., 437, 51-61.

49. Zhang, H., Wang, X., Chen, Z. and Wang, W. (2015) MicroRNA-424 suppresses estradiol-induced cell proliferation via targeting GPER in endometrial cancer cells. Cell. Mol. Biol., 61, 96-101.

50. Lu, Z., Nian, Z., Jingjing, Z., Tao, L. and Quan, L. (2017) MicroRNA-424/E2F6 feedback loop modulates cell invasion, migration and EMT in endometrial carcinoma. Oncotarget, 8, 114281-114291.

51. Krakstad, C., Trovik, J., Wik, E., Engelsen, I.B., Werner, H.M., Birkeland, E., Raeder, M.B., Oyan, A.M., Stefansson, I.M., Kalland, K.H., Akslen, L.A. and Salvesen, H.B. (2012) Loss of GPER identifies new targets for therapy among a subgroup of ERalpha-positive endometrial cancer patients with poor outcome. Br. J. Cancer, 106, 1682-1688.

52. Jala, V.R., Radde, B.N., Haribabu, B. and Klinge, C.M. (2012) Enhanced expression of G-protein coupled estrogen receptor (GPER/GPR30) in lung cancer. BMC Cancer, 12, 624.

53. Zhang, K.S., Chen, H.Q., Chen, Y.S., Qiu, K.F., Zheng, X.B., Li, G.C., Yang, H.D. and Wen, C.J. (2014) Bisphenol A stimulates human lung cancer cell migration via upregulation of matrix metalloproteinases by GPER/EGFR/ERK1/2 signal pathway. Biomed. Pharmacother, 68, 1037-1043.

54. Hsu, L.H., Chu, N.M. and Kao, S.H. (2017) Estrogen, estrogen receptor and lung cancer. Int. J. Mol. Sci., 18, E1713.

55. Jacenik, D., Cygankiewicz, A.I. and Krajewska, W.M. (2016) The G protein-coupled estrogen receptor as a modulator of neoplastic transformation. Mol. Cell. Endocrinol., 429, 10-18.

56. Zhu, G., Huang, Y., Wu, C., Wei, D. and Shi, Y. (2016) Activation of G-protein-coupled estrogen receptor inhibits the migration of human nonsmall cell lung cancer cells via IKKbeta/NF-kappaB signals. DNA Cell Biol., 35, 434-442.

57. Avino, S., De Marco, P., Cirillo, F., Santolla, M.F., De Francesco, E.M., Perri, M.G., Rigiracciolo, D., Dolce, V., Belfiore, A., Maggiolini, M., Lappano, R. and Vivacqua, A. (2016) Stimulatory actions of IGF-I are mediated by IGF-IR cross-talk with GPER and DDR1 in mesothelioma and lung cancer cells. Oncotarget, 7, 52710-52728.

58. Liu, Q., Chen, Z., Jiang, G., Zhou, Y., Yang, X., Huang, H., Liu, H., Du, J. and Wang, H. (2017) Epigenetic down regu- lation of G protein-coupled estrogen receptor (GPER) functions as a tumor suppressor in colorectal cancer. Mol. Cancer, 16, 87.

59. Gilligan, L.C., Gondal, A., Tang, V., Hussain, M.T., Arvaniti, A., Hewitt, A.M. and Foster, P.A. (2017) Estrone sulfate transport and steroid sulfatase activity in colorectal cancer: implications for hormone replacement therapy. Front. Pharmacol., 8, 103.

60. Santolla, M.F., Lappano, R., De Marco, P., Pupo, M., Vivacqua, A., Sisci, D., Abonante, S., Iacopetta, D., Cappello, A.R., Dolce, V. and Maggiolini, M. (2012) G protein-coupled estrogen receptor mediates the up-regulation of fatty acid synthase induced by 17 beta-estradiol in cancer cells and cancer-associated fibroblasts. J. Biol. Chem., 287, 43234-43245.

61. Bustos, V., Nolan, A.M., Nijhuis, A., Harvey, H., Parker, A., Poulsom, R., McBryan, J., Thomas, W., Silver, A. and Harvey, B.J. (2017) GPER mediates differential effects of estrogen on colon cancer cell proliferation and migration under normoxic and hypoxic conditions. Oncotarget, 8, 8425884275.

62. Chimento, A., Sirianni, R., Casaburi, I., Zolea, F., Rizza, P., Avena, P., Malivindi, R., De Luca, A., Campana, C., Martire, E., Domanico, F., Fallo, F., Carpinelli, G., Cerquetti, L., Amendola, D., Stigliano, A. and Pezzi, V. (2015) GPER agonist G-1 decreases adrenocortical carcinoma (ACC) cell growth in vitro and in vivo. Oncotarget, 6, 19190-19203.

63. Chan, Q.K., Lam, H.M., Ng, C.F., Lee, A.Y., Chan, E.S., Ng, H.K., Ho, S.M. and Lau, K.M. (2010) Activation of GPR30 inhibits the growth of prostate cancer cells through sustained activation of Erk1/2, c-jun/c-fos-dependent upregulation of p21, and induction of G(2) cell-cycle arrest. Cell Death Differ., 17, 1511-1523.

64. Pisolato, R., Lombardi, A.P., Vicente, C.M., Lucas, T.F., Lazari, M.F. and Porto, C.S. (2016) Expression and regulation of the estrogen receptors in PC-3 human prostate cancer cells. Steroids, 107, 74-86.

65. Lau, K.M. and To, K.F. (2016) Importance of estrogenic signaling and its mediated receptors in prostate cancer. Int. J. Mol. Sci., 17, E1434.

66. Lau, K.M., Ma, F.M., Xia, J.T., Chan, Q.K.Y., Ng, C.F. and To, K.F. (2017) Activation of GPR30 stimulates GTP-binding of Galphail protein to sustain activation of Erk1/2 in inhibition of prostate cancer cell growth and modulates metastatic properties. Exp. Cell Res., 350, 199-209.

67. Lam, H.M., Ouyang, B., Chen, J., Ying, J., Wang, J., Wu, C.L., Jia, L., Medvedovic, M., Vessella, R.L. and Ho, S.M. (2014) Targeting GPR30 with G-1: a new therapeutic target for castration-resistant prostate cancer. Endocr. Relat. Cancer, 21, 903-914.

68. Jia, B., Gao, Y., Li, M., Shi, J., Peng, Y., Du, X., Klocker, H., Sampson, N., Shen, Y., Liu, M. and Zhang, J. (2016) GPR30 Promotes prostate stromal cell activation via suppression of ERalpha expression and its downstream signaling pathway. Endocrinology, 157, 3023-3035.

69. Williams, G. (2012) Aromatase up-regulation, insulin and raised intracellular oestrogens in men, induce adiposity, metabolic syndrome and prostate disease, via aberrant ER-alpha and GPER signalling. Mol. Cell. Endocrinol., 351, 269-278. 